\title{
O-naphthoquinone isolated from Capraria biflora L. induces selective cytotoxicity in tumor cell lines
}

\author{
G.G.N. de S. Wisintainer ${ }^{1}$, G. Scola ${ }^{2}$, S. Moura ${ }^{3}$, T.L.G. Lemos ${ }^{4}$, C. Pessoa ${ }^{5,6}$, \\ M.O. de Moraes ${ }^{5}$, L.G.S. Souza ${ }^{4}$, M. Roesch-Ely ${ }^{1}$ and J.A.P. Henriques ${ }^{1}$ \\ 'Laboratório de Genômica, Proteômica e Reparo de DNA, \\ Universidade de Caxias do Sul, RS, Brasil \\ ${ }^{2}$ University of Toronto and Centre for Addiciton and Mental Health, ON, Canada \\ ${ }^{3}$ Laboratório de Biotecnologia de Produtos Naturais e Sintéticos, \\ Universidade de Caxias do Sul, RS, Brasil \\ ${ }^{4}$ Departamento de Química Orgânica e Inorgânica da Universidade Federal do Ceará, \\ Fortaleza, CE, Brasil \\ ${ }^{5}$ Laboratório de Oncologia Experimental, \\ Departamento de Fisiologia e Farmacologia, Faculdade de Medicina, \\ Universidade Federal do Ceará, Fortaleza, CE, Brasil \\ ${ }^{6}$ Fundação Oswaldo Cruz-Ceará, Fortaleza, CE, Brasil \\ Corresponding author: J.A.P. Henriques \\ E-mail: pegas.henriques@gmail.com. \\ Genet. Mol. Res. 14 (4): 17472-17481 (2015) \\ Received July 10, 2015 \\ Accepted September 18, 2015 \\ Published December 21, 2015 \\ DOI http://dx.doi.org/10.4238/2015.December.21.18
}

ABSTRACT. Biflorin is an o-naphthoquinone isolated from the roots of the plant Capraria biflora L. (Scrophulariaceae). In this study, the cytotoxic effects of biflorin were verified, and late apoptosis was detected in various cancer cell lines by in situ analysis. The cytotoxicity was further evaluated exclusively for $48 \mathrm{~h}$ of treatment in different tumor and non-tumor cell lines (Hep-2, HeLa, HT-29, A-375, and A-549, and HEK-293, respectively). The results indicated that biflorin induced selective cytotoxicity in tumor cells. HeLa cells were more susceptible to biflorin, followed by HT-29, A-549, 
A-375, and Hep-2 at all concentrations (range 5-50 $\mu \mathrm{g} / \mathrm{mL}$ ), and the highest half-maximal inhibitory concentration $\mathrm{IC}_{50}(56.01 \pm 1.17 \mu \mathrm{g} / \mathrm{mL})$ was observed in HEK-293 cells. Late apoptotic/necrotic events, observed by in situ immunostaining with Annexin $\mathrm{V}$, varied with each cell line; an increase in late apoptotic events was observed corresponding to the increase in biflorin dosage. Hep-2 cells showed a greater percentage of late apoptotic events among the tumor cell lines when treated with higher concentrations of biflorin (69.63 $\pm 2.28 \%)$. The non-tumor HEK-293 line showed greater resistance to late apoptotic events, as well as a lower level of cytotoxicity $(77.69 \pm 6.68 \%)$ than the tested tumor lines. The data presented indicate that biflorin showed an important, possibly selective, cytotoxicity against tumor cell lines, thereby revealing a promising novel substance with potential anticancer activity for tumor therapy.

Key words: Apoptosis; Biflorin; Cytotoxicity; O-naphthoquinone; Tumor

\section{INTRODUCTION}

Capraria biflora L. (Scrophulariaceae) is a perennial shrub distributed throughout North and South America (Wisintainer et al., 2014). Phytochemical investigations of this plant species have led to the isolation and characterization of biflorin [6,9-dimethyl-3-(4-methyl-3-pentenyl) naphtha [1,8-bc]pyran-7,8-dione] from its roots (Fonseca et al., 2003). Biflorin is an o-naphthoquinone with proven cytotoxic effects against tumor cells (anti-tumor), as well as anti-microbial and antimutagenic activities (Wisintainer et al., 2014). It is also strongly active against gram-positive and alcohol-acid-resistant bacteria (Gonçalves de Lima et al., 1958).

Biflorin has been shown to inhibit the proliferation of five tumor cell lines (CEM, HL-60, B16, $\mathrm{HCT}-8$, and MCF-7) in a dose-dependent manner, at concentrations ranging from 0.39 to $25 \mathrm{\mu g} /$ $\mathrm{mL}$ (Vasconcellos et al., 2005). Moreover, 1-20 $\mu \mathrm{M}$ biflorin exerted a cytotoxic effect on the SK-Br3 cell line (Montenegro et al., 2013b). A previous study also suggested that biflorin acts by inhibiting $\mathrm{N}$-cadherin function in MDA-MB-435 melanoma cells; inhibitors of $\mathrm{N}$-cadherin function have been reported to cause apoptosis and regulate the AKT-1 pathway (Montenegro et al., 2013b).

The antitumor activity of biflorin has also been evaluated in vivo in animals transplanted with Sarcoma 180 and Ehrlich carcinoma. A histopathological exam of the spleen, kidney, and liver of these transplanted animals displayed the promising antitumor effects and low toxicity of biflorin (Vasconcellos et al., 2007). Mouse in vivo studies have also revealed that biflorin coupling increased the effectiveness of 5-fluoracil chemotherapy (5-FU), and reduced the systemic toxicity (Vasconcellos et al., 2007). Moreover, the administration of $25 \mathrm{mg} /$ day biflorin to animals transplanted with melanoma B16 for ten days induced significant tumor growth inhibition with no systemic toxicity (Vasconcellos et al., 2011).

However, there have been no reports on the selective cytotoxicity and effects of biflorin on the morphological changes and induction of apoptosis (in conjunction with annexin $\mathrm{V}$ ) on tumor cells, apart from the cytotoxic screening of biflorin treatment in tumor cell lines. In this study, we evaluated the cytotoxic activity of biflorin in the tumor cell lines Hep-2 (human larynx carcinoma), HeLa (human cervical adenocarcinoma), HT-29 (human colon cancer), and A-375 (human melanoma), A-549 (human alveolar epithelial), and the non-tumor line HEK-293 (human embryonic kidney). We also attempted to determine the morphological aspects of the cells and induction of apoptosis after biflorin treatment via in situ analyses. 


\section{MATERIAL AND METHODS}

\section{Isolation of biflorin}

Capraria biflora was collected from a plantation located in Fortaleza, Ceará, Brazil, in April 2005, and identified by Dr. Edson Nunes. A voucher specimen (No. 30848) was deposited in the Herbarium of the Federal University of Ceará. Air-dried powdered roots $(6 \mathrm{~kg})$ were extracted with light petroleum (4:I) for two days. The extract was partially evaporated at room temperature until the formation of a solid material was observed. The latter was filtered under vacuum and yielded purple solid compost $(2 \mathrm{~g})$. The purple solid material was subjected to Silica-gel chromatography, as well as isocratic elution using a binary mixture of light petroleum and EtOAc $(9: 1 \mathrm{v} / \mathrm{v})$. The fractions were pooled together based on the results of thin-layer chromatography (TLC). Combined fractions containing the purified biflorin yielded $1.5 \mathrm{~g}$ compound.

\section{Mass spectrometric (MS) analysis - chemical identification}

The dry fraction was dissolved in a mixture containing $50 \%(\mathrm{v} / \mathrm{v})$ chromatographic grade acetonitrile (Tedia, Fairfield, OH, USA), 50\% (v/v) deionized water, and $0.1 \%$ formic acid. The solution was infused directly into the electrospray ionisation (ESI) source at a flow rate of 100 $\mu \mathrm{L} . \mathrm{min}^{-1}$, with the assistance of a high performance liquid chromatograph (HPLC; Shimadzu, Tokyo, Japan). ESI (+)-MS and ESI (-)-MS were acquired using a hybrid high-resolution and high accuracy $(5 \mu \mathrm{L} / \mathrm{L})$ micro-time of flight (TOF) (Q-TOF) mass spectrometer (Bruker Scientific ${ }^{\circledR}$, Billerica, MA, USA) under the following conditions: capillary and cone voltage, $+3500 \mathrm{~V}$ and $+40 \mathrm{~V}$, respectively; and de-solvation temperature, $180^{\circ} \mathrm{C}$. A TOF control software (Bruker Scientific ${ }^{\circledR}$ ) was used for data acquisition and processing. The data was collected in an $\mathrm{m} / \mathrm{z}$ range of $70-800$ and at a speed of 2 scans/second; a resolution of 50,000 (FWHM) was obtained at $\mathrm{m} / \mathrm{z} 200$. No important ions were observed below m/z 100 or above m/z 600; therefore, the ESI (+)-MS data at the $\mathrm{m} / \mathrm{z}$ range 295-350 is shown.

\section{Cell culture and cytotoxic assay}

The Hep-2 (human larynx carcinoma), HeLa (human cervical adenocarcinoma), HT-29 (human colon cancer), A-375 (human melanoma), A-549 (human alveolar epithelial), and HEK293 (human embryonic kidney) cell lines were cultured in Dulbecco's modified Eagle's medium supplemented with antibiotics and 10\% fetal bovine serum (Gibco; Life Technologies, Carlsbad, CA, USA) at $5 \% \mathrm{CO}_{2}$ and $37^{\circ} \mathrm{C}$. In order to assess the cytotoxic activity, cells were seeded in 96well flat-bottom microplates at a density of approximately $5 \times 10^{4}$ cells/well. Following attachment, the cells were treated with serial dilutions of biflorin in culture media: in order to identify a suitable incubation time, HeLa and HEK-293 cells were incubated for 24,48 , and 72 h; the cytotoxic curve profiles for the different times of cultivation with biflorin were similar in these cells. Therefore, the 48 $\mathrm{h}$ incubation period was utilized to determine the cytotoxic activity of biflorin in all tumor cell lines.

The cell viability was determined using the tetrazolium salt assay (MTT) (Denizot and Lang, 1986). Briefly, $5 \times 10^{4}$ cells/well were cultured in 96-well plates, and treated with biflorin, dissolved in increasing concentrations $(5-50 \mu \mathrm{g} / \mathrm{mL})$ of dimethyl sulfoxide (DMSO), for $48 \mathrm{~h}$. DMSO was added after incubating the cells with MTT solution at room temperature for $2 \mathrm{~h}$; the absorption was determined at $540 \mathrm{~nm}$ (SpectraMAX M2/M2e; Molecular Devices, Sunnyvale, CA, USA). At 
least three independent experiments were performed for each experimental cell line, and the half maximal inhibitory concentration $\left(\mathrm{IC}_{50} ; \mu \mathrm{g} / \mathrm{mL}\right.$ ) was determined (Monks et al., 1991). Biflorin was prepared immediately prior to each treatment. The negative control was exposed to an equivalent concentration of DMSO solvent.

\section{Detection of late apoptosis by in situ analysis}

Apoptotic cell death was detected by in situ analysis using Annexin $\mathrm{V}$ staining and visualized by fluorescence microscopy. Hep-2, HeLa, HT-29, A-375, A-549, and HEK-293 cells were seeded $\left(1.0 \times 10^{5} \mathrm{cells} / \mathrm{mL}\right)$ on to coverslips in 24-well plates with $500 \mu \mathrm{L}$, supplemented culture media. After $24 \mathrm{~h}$, the cells were treated with 5, 10, and $40 \mu \mathrm{g} / \mathrm{mL}$ biflorin (negative controls were exposed to an equivalent concentration of DMSO) and incubated at $37^{\circ} \mathrm{C}$ under $5 \% \mathrm{CO}_{2}$ conditions for $48 \mathrm{~h}$. The media was subsequently removed, and the cells incubated with $2.5 \mu \mathrm{g} / \mathrm{mL}$ Annexin V (ab14196; Abcam, Cambridge, UK) primary antibody in binding buffer (HEPES $10 \mathrm{mM}, \mathrm{NaCl} 150 \mathrm{mM}, \mathrm{KCl} 5 \mathrm{mM}, \mathrm{MgCl}_{2} 1 \mathrm{mM}, \mathrm{CaCl}_{2} 1.8 \mathrm{mM}, \mathrm{pH} 7.4$ ) for 30 minutes. The cells were then washed once with binding buffer, and incubated with $2.5 \mu \mathrm{g} / \mathrm{mL}$ Dylight $^{\circledR} 488$ (ab115637; Abcam, Cambridge, UK) secondary antibody. The cells were also stained with propidium iodide (PI) to verify possible necrotic activation (P4170; Sigma-Aldrich, St. Louis, MO, USA). Results were expressed as the percentage of cells undergoing early stage (Annexin-V-positive) or late stage (Annexin-V-positive/ PI-positive) apoptosis: at least 500 cells were counted in 10 different fields in triplicate, and subsequently quantified as a percentage of the total number of cells.

\section{Statistical analyses}

The results are reported as means \pm standard deviation (SD) of each group. One-way analysis of variance (ANOVA) followed by the Tukey post hoc test was used to evaluate differences among the treatment groups. Statistical analyses were performed using the Statistical Package for the Social Sciences (SPSS 19.0) software (IBM, Armonk, NY, USA). The level of significance was uniformly set at $\mathrm{P}<0.05$.

\section{RESULTS}

\section{Isolation and chemical characterization of biflorin}

In this study, ESI (+)-MS and tandem ESI (+)-MS/MS were acquired using a microTOF-Q II (Q-TOF), and the spectra from biflorin is displayed in Figure 1. Accordingly, the $\mathrm{m} / \mathrm{z} 309.1483$ $[\mathrm{M}+\mathrm{H}]+$ and $331.1286[\mathrm{M}+\mathrm{Na}]+$ matched the molecular formula $\mathrm{C}_{20} \mathrm{H}_{21} \mathrm{O}_{3}$ and $\mathrm{C}_{20} \mathrm{H}_{21} \mathrm{O}_{3} \mathrm{Na}$ with the experimental difference 2.49 and $7.29 \mathrm{ppm}$, respectively (Figure 1). The isotopic ratio of $[\mathrm{M}+\mathrm{H}]+$ is confirmatory with the $\mathrm{m} / \mathrm{z}$ ratio of $310.1511(22.85 \%)$ and $311.1530(2.67 \%)$. There were no ions in the mass spectra in positive mode ESI (+) beyond those reported (Figure 1). In negative mode ESI (-) wherein ammonium hydroxide $(0.1 \%)$ was used in solution, no answer was expected because of the poor ionization of this functional group. This set of results confirmed the purity of the compound. 


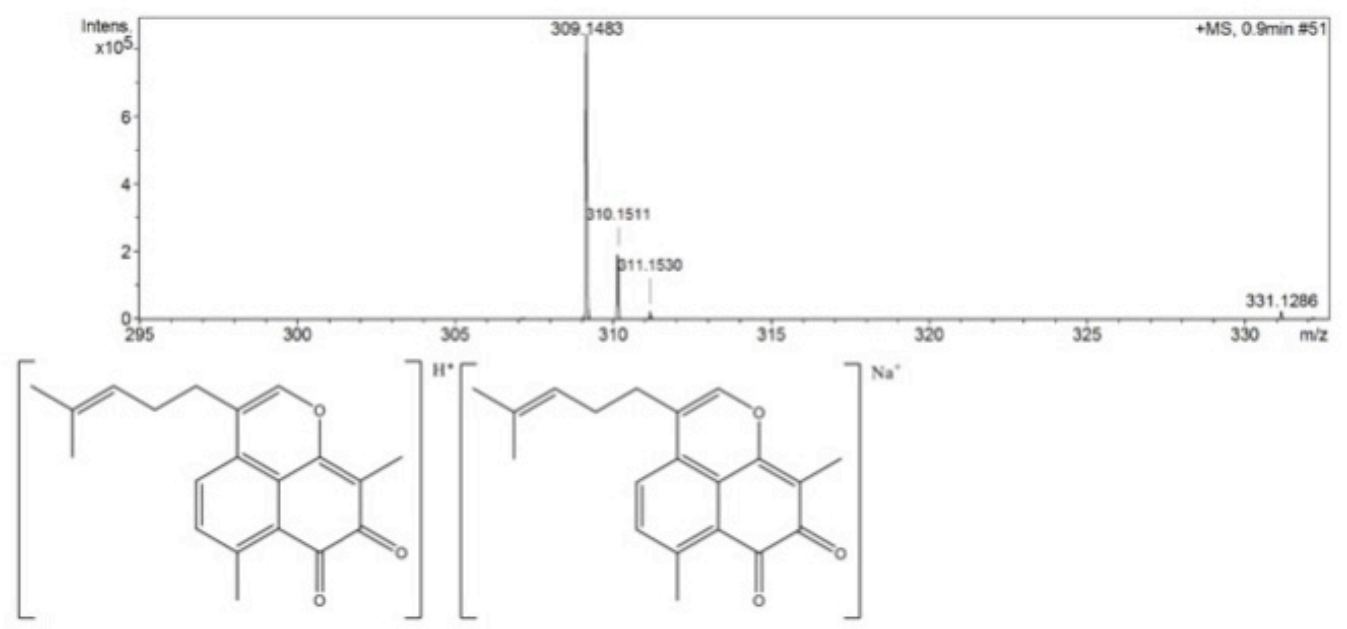

Figure 1. ESI (+) mass spectra of biflorin (6,9-dimethyl-3-(4-methyl-3-pentenyl) naphtha[1,8-bc]-pyran-7,8-dione), highlighting adducts chemical structures $[\mathrm{M}+\mathrm{H}]+$ and $[\mathrm{M}+\mathrm{Na}]+$ at $\mathrm{m} / \mathrm{z} 309.1483$ and 331.1286 , respectively.

\section{Cytotoxicity assay}

Initially, the tumor line HeLa and non-tumor cell line HEK-293 were treated with biflorin at a range of $5-50 \mu \mathrm{g} / \mathrm{mL}$ for 24,48 , and $72 \mathrm{~h}$ (Figure 2). A selective cytotoxicity was observed in HeLa (Figure 2A), compared to the HEK-293 (Figure 2B) cells. The cytotoxicity was further evaluated exclusively at $48 \mathrm{~h}$ of treatment on six different cell lines (Hep-2, HeLa, HT-29, A-375, A-549, and HEK-293) and the half-maximal inhibitory concentration $\left(\mathrm{IC}_{50}\right)$ is presented in Figure 3. HeLa cells were more susceptible to biflorin, followed by HT-29, A-549, A-375, and Hep-2 at all tested concentrations $(5-50 \mu \mathrm{g} / \mathrm{mL})$; the highest $I_{50}$ value $(56.01 \pm 1.17 \mu \mathrm{g} / \mathrm{mL})$ was exhibited by the HEK-293 cell line. Given the increased susceptibility of HeLa to the cytotoxic effect of biflorin, this cell line was selected for further morphological analyses using Giemsa staining. Substantial morphological changes in HeLa cells were observed after $48 \mathrm{~h}$ of treatment with increasing concentrations of biflorin $(5-50 \mu \mathrm{g} / \mathrm{mL}$; Figure 4$)$.

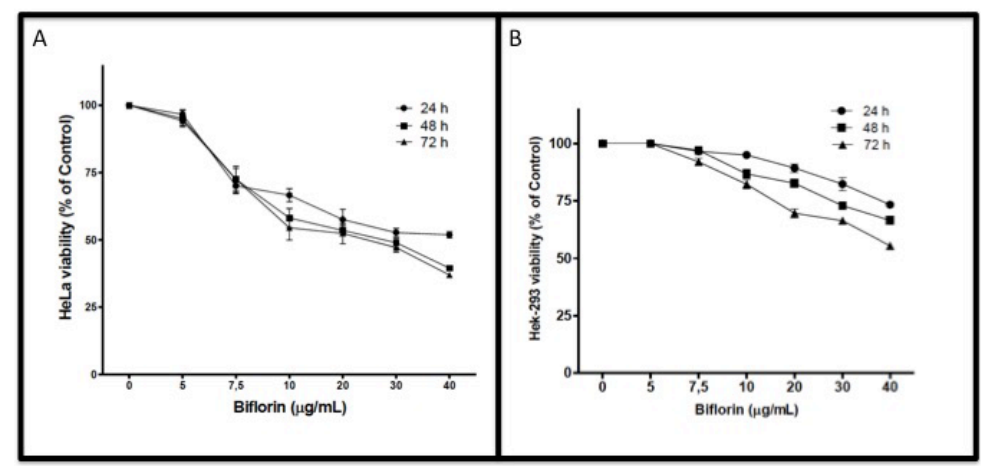

Figure 2. Cytotoxic effect of biflorin extracts on the viability of HeLa (A) and HEK-293 (B) cell lines. Cells were treated for 24,48 , and $72 \mathrm{~h}$ with $5,7.5,10,20,30$, and $40 \mu \mathrm{g} / \mathrm{mL}$ biflorin. Results are reported as means \pm standard deviation (SD) for triplicate experiments. 


\section{Cell lines $-\mathrm{IC}_{50}$}

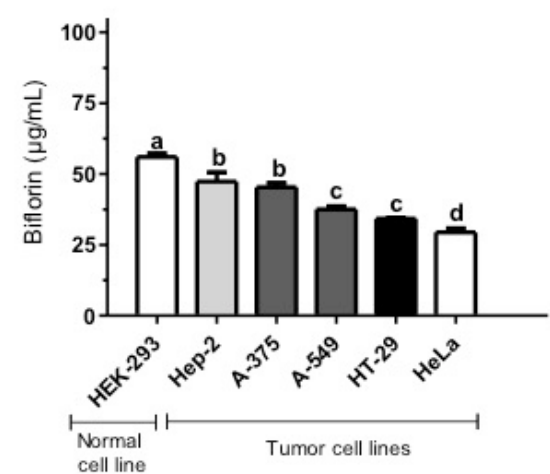

Figure 3. Half maximal inhibitory concentration $\left(\mathrm{IC}_{50}\right)$ of biflorin (after $48 \mathrm{~h}$ treatment) in different cell lines; $\mathrm{IC}_{50}(\mu \mathrm{g} /$ $\mathrm{mL}$ ) is reported as means $\pm \mathrm{SD}$. Different letters indicate the level of significance determined by one-way ANOVA followed by Tukey post hoc analysis $(P<0.05)$ used to examine the difference between treatment groups against the appropriate control (HEK-293).

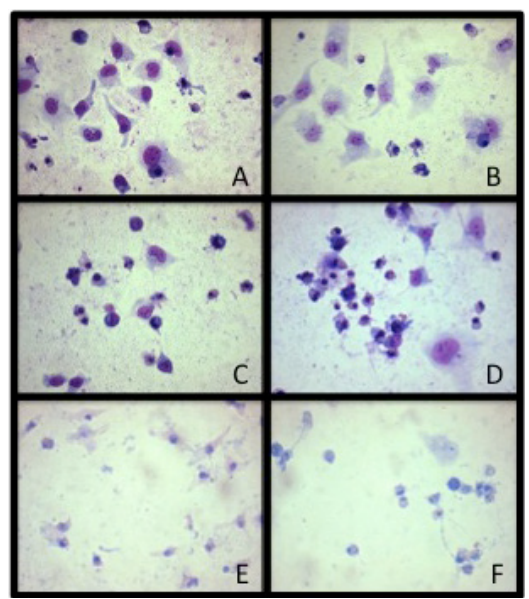

Figure 4. Morphological changes in HeLa cells treated with biflorin $(5-50 \mu \mathrm{g} / \mathrm{mL})$ for $48 \mathrm{~h}$. Photomicrographs were taken under a light microscope (200X). Cells treated with different concentrations of biflorin: A. $5 \mu \mathrm{g} / \mathrm{mL} ;$ B. $7.5 \mu \mathrm{g} / \mathrm{mL}$; C. $10 \mu \mathrm{g} / \mathrm{mL}$; D. $20 \mu \mathrm{g} / \mathrm{mL}$; E. $30 \mu \mathrm{g} / \mathrm{mL}$; and F. $40 \mu \mathrm{g} / \mathrm{mL}$ were stained with Giemsa.

\section{Detection of late apoptosis by in situ analysis}

Biflorin induced apoptosis in Hep-2, A-375, A-549, HT-29, and HeLa tumor cells. In situ Annexin $\mathrm{V}$ immunostaining showed that a majority of the cells from all cell lines were at a late apoptotic stage in a biflorin dose-dependent manner. Annexin $\mathrm{V}+/ \mathrm{PI}$ - cells indicate phosphatidylserine detection on the external surface of an intact plasma membrane (green fluorescence). PI + (red fluorescence) in conjunction with Annexin $\mathrm{V}+$ (Merge) labeling in cells indicate a compromised membrane that may be a result of either late apoptotic or necrotic activation. Late apoptosis/necrosis events varied according to the lines analyzed. In general, all cells presented an increase in late apoptotic activation when treated with higher doses of biflorin. Interestingly, late apoptosis events 
started at lower concentrations of biflorin $(10 \mu \mathrm{g} / \mathrm{mL}$ ) in all tumor lines (Figure 5). Hep-2 cells showed greater values when treated with higher concentrations $(40 \mu \mathrm{g} / \mathrm{mL})$ of biflorin $(69.63 \pm 2.28 \%)$. The non-tumor HEK-293 cell line showed more resistance to apoptosis activation; however, late apoptotic events were visible after treatment with higher concentrations of biflorin $(77.69 \pm 6.68 \%)$.
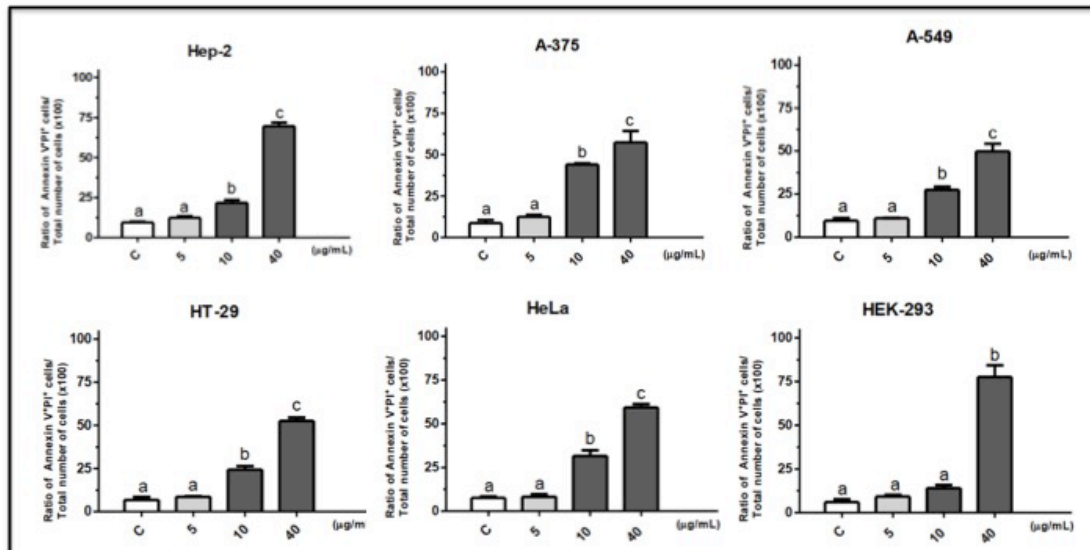

Figure 5. Detection of apoptosis by in situ analysis with PS-binding Annexin V in biflorin-treated Hep-2, A-375, A-549, HT-29, HeLa, and HEK-293 cells (48 h). The letter $\mathrm{C}$ represents the negative solvent control. Different letters indicate the level of significance, as tested by one-way ANOVA followed by the Tukey post hoc test $(P<0.05)$, compared to the control.

\section{DISCUSSION}

Natural products have played an important role in the treatment and prevention of human diseases. Furthermore, $60 \%$ of the drugs currently used have their origin related to natural sources. Among the sources found in nature, plants have made the single largest contribution to the development of therapeutic substances (Kirkpatrick, 2002). Quinones are secondary metabolites found in several plants and present a variety of biological effects, including anticancer, antibacterial, and antimalarial effects. In particular, naphthoquinones, which include biflorin, belong to a promising group of compounds with antitumor properties (Asche, 2005). Moreover, quinone moieties are present in many drugs, such as anthracyclines, daunorubicin, doxorubicin, mitomycin, mitoxantrone, and saintopin, which are clinically used in the treatment of solid cancers (Verma, 2006).

Despite previous studies using in vitro and in vivo models indicating that biflorin presents potential antitumor activity, there have been no reports on its selective cytotoxicity. Additionally, its effects on the morphological changes and induction of apoptosis in tumor cell lines have not been described. In this study, the cytotoxic activity of biflorin was evaluated in five tumor lines (Hep-2, HeLa, HT-29, A-375, and A-549), and compared these effects to those seen in non-tumor Hek-293 cells. The morphological aspects of biflorin-treated HeLa cells were also investigated, and the induction of apoptosis was evaluated in all cell lines by in situ analysis. We observed that the same concentration of biflorin was able to inhibit cell proliferation more effectively in tumor cells $(5-50 \mu \mathrm{g} /$ $\mathrm{mL})$ than in the Hek-293 cells $(56.01 \mu \mathrm{g} / \mathrm{mL})$.

The effect of biflorin on different tumor cell lines have been previously screened at a range of biflorin concentrations $(0.39-25 \mu \mathrm{g} / \mathrm{mL})$ similar to the one reported in this study $(5-50 \mu \mathrm{g} / \mathrm{mL})$ (Vasconcellos et al., 2005, 2007, 2011). Recently, Montenegro et al. (2013a) revealed that biflorin 
(1-20 $\mu \mathrm{M})$ exerted cytotoxic effects on breast cancer SK-Be3 cells; additionally, biflorin treatment was seen to exert selective cytotoxicity against cancer cells in relation to normal cells, as observed in this study. The authors also demonstrated that the inhibition of cell proliferation by biflorin could be mediated through the down-regulation of the EGFR signaling pathway, as biflorin decreases the total EGFR expression (Montenegro et al., 2013a).

The selective induction of cell death plays a major role in decreasing the possible side effects of chemotherapy (Reichert and Wenger, 2008; Parkinson et al., 2013). The relation between cancer and apoptosis has being emphasized for a long time, suggesting that tumor progression involves the inhibition of apoptotic stages in tumor cells (Yang et al., 2006; Vasconcellos et al., 2011). Apoptosis, autophagy, and necrosis are the three main forms of cell death, each one presenting a unique set of biochemical and morphological changes that occur within the dying cell (Elmore, 2007; Ouyang et al., 2012). Moreover, apoptosis is a programmed form of cell death observed in tissues during development, and maintains tissue homeostasis through the elimination of excessive or injured cells (Ouyang et al., 2012; Solá et al., 2013).

Substantial morphological changes in HeLa cells were observed when treated with increasing concentrations $(5-50 \mu \mathrm{g} / \mathrm{mL})$ of biflorn for $48 \mathrm{~h}$, through Giemsa staining. In situ immunostaining with Annexin $\mathrm{V}$ showed that the cells were mainly at the late apoptotic stages. Late apoptosis was more evident $(77.69 \pm 6.68 \%)$ in the non-tumor line HEK-293 treated with higher concentrations of biflorin, compared to the tested tumor cell lines, which may indicate the resistance of non-tumor cells and a specific selectivity of the compound. Exposure of PS anionic phospholipids at the outer leaflet of the plasma membrane is correlated with the loss of asymmetry in the cell membrane, and plays a physiological role in the recognition and subsequent removal of the dying cell via phagocytosis (Poon et al., 2010). This phenomenon permits the detection and differentiation of apoptotic cell death from necrosis. The staining of cells by membrane impermeable dyes such PI allows one to differentiate between early apoptosis and late apoptosis/ necrosis (Elmore, 2007).

Evidence suggests that tumor cells with changes in apoptotic function may diverge to another means of cell death such as necrosis, thereby promoting an alternative therapeutic approach (Zong et al., 2004; Degenhardt et al., 2006; Zong and Thompson, 2006). Necrosis may rise as a result of errors in apoptotic function, which could also induce alterations in the glucose metabolism. Although necrosis can be considered a less efficient mechanism of cell death compared to apoptosis, defective apoptotic tumor cells may be more susceptible to therapy despite the possible consequences, such as inflammation (Degenhardt et al., 2006).

Many therapeutic agents for cancer, such as cisplatin, paclitaxel, isothiocyanate, and adriamycin, eliminate tumor cells by inducing apoptotic cell death (Tan et al., 2009; Hanahan and Weinberg, 2011). Tumor growth can be determined by the speed with which tumor cells progress towards death and elimination, in addition to the progression of malignant cells (Mester and Redeuilh, 2008). Therefore, the inhibition of tumor growth and induction of tumor cell death are elective therapeutic strategies for the control of tumor progression (Yang et al., 2006). The activation of programmed cell death should specifically target tumor cells, minimizing the side effects of inappropriate apoptosis induction in normal cells. Therefore, the development of new treatment strategies for cancer is crucial. Specifically, multiple pathways of cell death and the molecular mechanisms involved in carcinogenesis must be thoroughly elucidated.

These are preliminary results and should be interpreted in light of their limitations. Although cancer cell lines are an established model for the study of molecular mechanisms of anti-cancer phytometabolites, the use of cancer stem cells may help in better understanding the regulation of 
cell dynamics by the phytometabolite biflorin. Secondly, this study used imaging techniques and immunocytochemistry to verify and quantify the death pathway activation. Necessary parameters were taken to ensure the consistency of acquisition measurements; however, immunofluorescence is a limited and semi-quantitative method. The use of more sensitive techniques, such as real-time polymerase chain reaction (RT-PCR), is strongly advocated for future studies to confirm these findings. Finally, exploratory analyses of a broader range of factors, including the changes in expression patterns of specific proteins and alterations in DNA, such as locus-specific methylation and demethylation changes, would help further clarify the mechanism of biflorin. Future studies that explore these factors may allow for the validation of biflorin as a potential therapeutic agent.

\section{Conflicts of interest}

The authors declare no conflict of interest.

\section{ACKNOWLEDGMENTS}

Research supported by grants from CNPq (Conselho Nacional de Desenvolvimento Científico e Tecnológico, Brazil), CAPES (Coordenação de Aperfeiçoamento de Pessoal de Nível Superior), and FUNCAP (Fundação Cearense de Apoio ao Desenvolvimento Científico e Tecnológico, Brazil).

\section{REFERENCES}

Asche C (2005). Antitumour quinones. Mini. Rev. Med. Chem. 5: 449-467.

Degenhardt K, Mathew R, Beaudoin B, Bray K, et al. (2006). Autophagy promotes tumor cell survival and restricts necrosis, inflammation, and tumorigenesis. Cancer Cell 10: 51-64.

Denizot F and Lang R (1986). Rapid colorimetric assay for cell growth and survival. Modifications to the tetrazolium dye procedure giving improved sensitivity and reliability. J. Immunol. Methods 89: 271-277.

Elmore S (2007). Apoptosis: a review of programmed cell death. Toxicol. Pathol. 35: 495-516.

Fonseca AM, Pessoa ODL, Silveira ER, Monte FJQ, et al. (2003). Total assignments of $1 \mathrm{H}$ and $13 \mathrm{C}$ NMR spectra of biflorin and bis-biflorin from Capraria biflora. Magn. Reson. Chem. 41: 1038-1040.

Gonçalves de Lima O, D’Albuquerque IL, Neto BM and Albuquerque MM (1958). Breve Nota Sobre a Atividade Antimicrobiana da Biflorina Purificada por Partição Graig. Purificada por Partição Graig. Rev. Inst. Antibiot. 1: 95-97.

Hanahan D and Weinberg RA (2011). Hallmarks of cancer: the next generation. Cell 144: 646-674.

Kirkpatrick P (2002). Antibacterial drugs: Stitching together naturally. Nat. Rev. Drug Disc. 1: 748.

Mester $\mathrm{J}$ and Redeuilh G (2008). Proliferation of breast cancer cells: regulation, mediators, targets for therapy. Anticancer Agents Med. Chem. 8: 872-885.

Monks A, Scudiero D, Skehan P, Shoemaker R, et al. (1991). Feasibility of a high-flux anticancer drug screen using a diverse panel of cultured human tumor cell lines. J. Natl. Cancer Inst. 83: 757-766.

Montenegro R, Burbano R, Silva M, Lemos T, et al. (2013a). Biflorin, a naphthoquinone, inhibits egfr in breast cancer cells. Med. Chem. 3: 179-182.

Montenegro RC, de Vasconcellos MC, Barbosa GOS, Burbano RM, et al. (2013b). A novel o-naphtoquinone inhibits N-cadherin expression and blocks melanoma cell invasion via AKT signaling. Toxicol. in vitro. 27: 2076-2083.

Ouyang L, Shi Z, Zhao S, Wang FT, et al. (2012). Programmed cell death pathways in cancer: a review of apoptosis, autophagy and programmed necrosis. Cell Prolif. 45: 487-498.

Parkinson EI, Bair JS, Cismesia M and Hergenrother PJ (2013). Efficient NQO1 substrates are potent and selective anticancer agents. ACS Chem. Biol. 8: 2173-2183.

Poon IK, Hulett MD and Parish CR (2010). Molecular mechanisms of late apoptotic/necrotic cell clearance. Cell Death Differ. 17: 381-397.

Reichert JM and Wenger JB (2008). Development trends for new cancer therapeutics and vaccines. Drug Discov. Today 13: 30-37.

Solá S, Morgado AL and Rodrigues CM (2013). Death receptors and mitochondria: two prime triggers of neural apoptosis and differentiation. Biochim. Biophys. Acta 1830: 2160-2166. 
Tan ML, Ooi JP, Ismail N, Moad Al, et al. (2009). Programmed cell death pathways and current antitumor targets. Pharm. Res. 26: $1547-1560$.

Vasconcellos MC, Montenegro RC, Militão GC, Fonseca AM, et al. (2005). Bioactivity of biflorin, a typical o-naphthoquinone isolated from Capraria biflora L. Z. Naturforsch C. 60: 394-398.

Vasconcellos MC, Bezerra DP, Fonseca AM, Pereira MR, et al. (2007). Antitumor activity of biflorin, an o-naphthoquinone isolated from Capraria biflora. Biol. Pharm. Bull. 30: 1416-1421.

Vasconcellos MC, Bezerra DP, Fonseca AM, Araújo AJ, et al. (2011). The in-vitro and in-vivo inhibitory activity of biflorin in melanoma. Melanoma Res. 21: 106-114.

Verma RP (2006). Anti-cancer activities of 1,4-naphthoquinones: a QSAR study. Anticancer Agents Med. Chem. 6: 489-499.

Wisintainer GG, Simões ER, Lemos TL, Moura S, et al. (2014). Biflorin: an o-naphthoquinone of clinical significance. An. Acad. Bras. Cienc. 86: 1907-1914.

Yang HL, Chen CS, Chang WH, Lu FJ, et al. (2006). Growth inhibition and induction of apoptosis in MCF-7 breast cancer cells by Antrodia camphorata. Cancer Lett. 231: 215-227.

Zong WX and Thompson CB (2006). Necrotic death as a cell fate. Genes Dev. 20: 1-15.

Zong WX, Ditsworth D, Bauer DE, Wang ZQ, et al. (2004). Alkylating DNA damage stimulates a regulated form of necrotic cell death. Genes Dev. 18: 1272-1282. 